\title{
Amusia and its electrophysiological correlates in neurofibromatosis type 1
}

\author{
Amusia e seus correlatos eletrofisiológicos na neurofibromatose tipo 1 \\ Bruno Cézar Lage Cota’, João Gabriel Marques Fonseca², Luiz Oswaldo Carneiro Rodrigues ${ }^{1}$, Nilton Alves de \\ Rezende', Pollyanna Barros Batista ${ }^{1}$, Vincent Michael Riccardi³, Luciana Macedo de Resende ${ }^{4}$
}

\begin{abstract}
Auditory processing deficits are common in people with neurofibromatosis type 1 (NF1) and they often report difficulties in musical performance. Objective: We investigated whether NF1 could be associated with amusia as well as with some impairment of primary auditory cortex activity. Methods: Eighteen people with NF1 and 22 healthy volunteers, matched for age, sex and educational level, were evaluated with the Montreal Battery Evaluation of Amusia - short version. The integrity of cortical primary auditory processing areas was evaluated by evoked potential mismatch negativity. Results: Amusia was correlated with NF1 ( $p=0.001$, odds ratio = 42.0, confidence interval 4.5-39.6). Patients with NF1 exhibited a greater prevalence of amusia than healthy controls (67\% vs. $4.5 \%)$ and difficulties in both melodic and temporal music perception. Worse performance on the Montreal Battery Evaluation of Amusia was correlated with a greater mismatch negativity latency in NF1 group. Conclusions: Amusia is a common feature in NF1 and may result from impairment of activity in primary auditory processing areas.
\end{abstract}

Keywords: neurofibromatosis 1; music; evoked potentials; auditory perceptual disorders; pitch discrimination.

\section{RESUMO}

Déficits de processamento auditivo são comuns em pessoas com neurofibromatose tipo 1 (NF1), que também se queixam frequentemente de dificuldades no desempenho musical. Objetivos: Nós investigamos se a NF1 poderia estar associada à amusia, assim como a algum comprometimento da atividade do córtex auditivo primário. Métodos: Dezoito pessoas com NF1 e 22 controles sem a doença, pareados por idade, sexo e nível educacional, foram avaliados por meio da versão reduzida da Bateria de Avaliação de Amusia de Montreal (MBEA). A integridade das áreas corticais primárias do processamento auditivo foi avaliada através do potencial evocado auditivo mismacth negativity (MMN). Resultados: A amusia correlacionou-se com a NF1 ( $p=0,001$, odds ratio = 42,0, intervalo de confiança 4,5-39,6). Os pacientes com NF1 apresentaram maior prevalência de amusia do que os controles saudáveis (67\% vs. 4,5\%) e dificuldades na percepção musical, tanto melódica quanto temporal. 0 desempenho pior na MBEA foi correlacionado com maiores latências do MMN no grupo NF1. Conclusões: A amusia é uma característica comum na NF1 e pode resultar do comprometimento da atividade de áreas de processamento auditivo primário.

Palavras-chave: Neurofibromatose tipo 1; música; potenciais evocados; transtornos da percepção auditiva; nível de discriminação sonora.

Neurofibromatosis type $1(\mathrm{NF} 1)$ is a genetic disease that affects about 1:3,000 individuals. Cognitive and psychological problems are common in individuals with $\mathrm{NF} 1$, and include language and auditory disorders, learning difficulties, attention deficits, and social impairment ${ }^{1,2}$. Some investigators consider this "cognitive profile" a result of cerebral disconnection caused by structural abnormalities in the cerebral white matter, as evidenced by magnetic resonance imaging $(\mathrm{MRI})^{3-6}$.
An auditory processing disorder - a condition that affects an individual's ability to understand speech - has recently been reported as a common finding in patients with $\mathrm{NF}^{7}$. This comorbidity is not entirely surprising as it falls within the language disorder category with which this patient population commonly presents. However, we have found that individuals with NF1 also frequently complain of poor musical aptitude, describing these issues as an inability to sing in rhythm or in tune, difficulty in

\footnotetext{
1 Universidade Federal de Minas Gerais, Hospital das Clínicas, Centro de Referência em Neurofibromatoses, Belo Horizonte MG, Brasil;

¿Universidade Federal de Minas Gerais, Faculdade de Medicina, Departamento de Clínica Médica, Belo Horizonte MG, Brasil;

${ }^{3}$ The Neurofibromatosis Institute, La Crescenta, CA, USA;

4 Universidade Federal de Minas Gerais, Faculdade de Medicina, Departamento de Fonoaudiologia, Belo Horizonte MG, Brasil.

Correspondence: Bruno Cézar Lage Cota; Centro de Referência em Neurofibromatoses do Hospital das Clínicas da UFMG; Alameda Álvaro Celso, 55; 30150260 Belo Horizonte MG, Brasil; Email: brucezar@hotmail.com.br

Support: CNPq, CAPES, FAPEMIG, Universidade Federal de Minas Gerais (UFMG) and Pró- Reitoria de Pesquisa da UFMG.

Conflict of interest: There is no conflict of interest to declare.

Received 20 December 2017; Accepted 03 February 2018
} 
playing or learning an instrument, and trouble dancing or clapping in synchrony with a song. These impaired musical abilities may result from a disorder described in the literature as "amusia”, which is defined as the inability to notice and reproduce music. This condition is often present in educated individuals who have normal exposure to music and no auditory deficits ${ }^{8,9}$.

Amusia can be acquired or congenital and may be related to a predominant impairment in musical perception: rhythm (beat deafness) or melody (tone deafness) ${ }^{8,9}$. Acquired amusia is typically attributed to brain lesions caused by trauma, tumors, or vascular events. These lesions occur in areas required for music processing and usually cause cognitive damage, such as executive, memory, or attention deficits ${ }^{10}$. In contrast, individuals with the congenital form of amusia (about 1.5\% to $4 \%$ of the general population $)^{11,12}$ have difficulty understanding nonverbal elements of language (e.g. constituents of prosody), but do not present with cognitive dysfunction, except for spatial orientation problems ${ }^{13}$. These individuals exhibit predominant impairments in melody perception ${ }^{9,14}$.

Congenital amusia is also understood to be a cerebral disconnection disorder, secondary to abnormalities in the arcuate fasciculus - the fiber tract that connects the temporal cortex to the inferior frontal cortex ${ }^{15-18}$. It should be noted that MRI studies on individuals with congenital amusia have shown no alterations in the auditory cortex gray matter ${ }^{15,16}$. These findings are compatible with electrophysiological recordings that have revealed intact auditory processing pathways in primary cortical areas of individuals with this condition, analyzed by mismatch negativity $(\mathrm{MMN})^{19}$, a long-latency auditory evoked potential related to auditory cognitive processing p $^{20,21,22}$.

The MMN reflects a pre-attentive memory trace produced as response to a repetitive and identical auditory stimulus. Any discriminable change in some aspect of a repeated sound (e.g. frequency, duration, or intensity) elicits a neuronal activity in primary auditory cortical areas, independent of the individual's attention. The MMN is registered as a negative peak deflection on an electroencephalogram, which occurs 100-250 ms after an auditory stimulus (Figure 1) 20,21,22.

Considering that a disconnection syndrome is common to both congenital amusia and NF1 cognitive profiles, as well as the recent finding that individuals with NF1 often have an auditory processing disorder and complain of poor musical ability, we explored whether amusia could be considered a common feature of NF1. Additionally, through electrophysiological analysis of hearing, we also investigated if there was any impairment in primary cortical areas related to auditory processing.

\section{METHODS}

This was a cross-sectional, observational, case-controlled study approved by the Ethics Committee of Federal University of Minas Gerais (\#4062315.7.0000.5149). Informed consent was obtained from all participants or their parents.

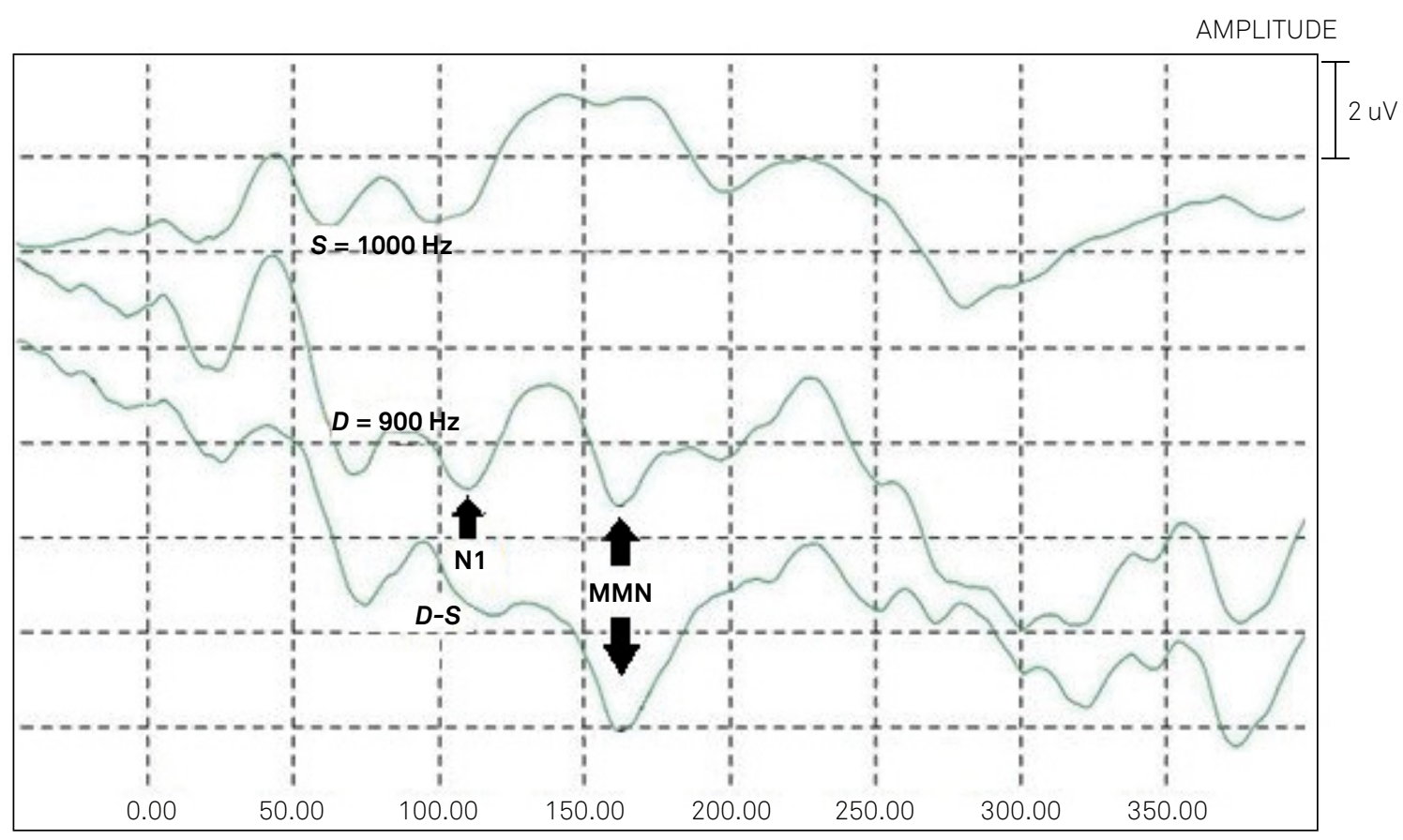

TIME (ms)

Figure 1. Mismatch negativity (MMN). Long latency auditory evoked potentials of a patient with NF1. The MMN is the additional negative peak after N1, here between $150 \mathrm{~ms}$ and $200 \mathrm{~ms}$, during a deviant stimulus trace (D), and its absence during a standard stimulus trace (S). The MMN is more evident in the trace corresponding to the subtraction of the standard stimulus from the deviant stimulus. 


\section{Study population}

The study sample consisted of 40 individuals aged between 16 and 35 years. The NF1 group comprised 18 patients who met at least three diagnostic criteria set by the National Institutes of Health for NF $1^{1}$. Patients were invited from the Neurofibromatosis Outpatient Reference Center of the Hospital das Clínicas of the Federal University of Minas Gerais, Belo Horizonte, Brazil, where they are evaluated and followed-up by a multiprofessional team. The control group consisted of 22 individuals using the Unified Health System, matched by sex, age, and education to the NF1 group.

\section{Exclusion criteria}

Through the medical records analysis and clinical interview, individuals with auditory loss, other neurological diseases or cognitive impairment that could interfere with the administered tests were excluded from participation in this study. Individuals with current musical practice or those who had studied music for longer than six months also met the exclusion criteria.

\section{Musical background questionnaire}

All participants answered a musical background questionnaire, which contained questions about previous musical study and experience.

\section{Peripheral auditory evaluation}

After undergoing otoscopy for evaluation of external auditory canal and tympanic membrane integrity, participants were submitted to a basic audiology evaluation (pure tone audiometry and speech audiometry ${ }^{23}$ ) to confirm the absence of auditory loss. Normal peripheral hearing was defined as an air conduction threshold of $25 \mathrm{~dB}$ hearing level or better at octave frequencies from $250 \mathrm{~Hz}$ to $8,000 \mathrm{~Hz}$ (ANSI S3.6). Participants were evaluated with an Interacoustics AD226 clinical audiometer in a quiet room with an ambient noise level of $30 \mathrm{~dB}$, using the procedure recommended by the ANSI S3-1991. A Homis model 910 decibel meter (Homis Controle e Instrumentação Ltda., São Paulo, Brazil) was used to measure sound intensity ( $\mathrm{dB}$ sound pressure level).

\section{Music processing assessment}

An evaluation of music perception was performed through a short version of the Montreal Battery Evaluation of Amusia (MBEA) proposed by Nunes-Silva and Haase ${ }^{24}$. The original MBEA version ${ }^{14}$ was validated and normalized for use in Brazil by the same authors. All versions evaluate six components of music processing: scale, contour, interval, rhythm, metric, and music memory. The test comprises novel musical phrases, composed according to the Western tonal system and executed by a computer with a piano tone. In the current study, sound stimuli were presented through earphones with filters; sound intensity was adjusted to a level considered comfortable by the participants, and testing was conducted in a soundproof, temperature-controlled room.

The MBEA-short version has approximately half the number of the full version items, and an average application time of 50 minutes. Testing was administered to all participants by the same examiner. The musical phrases used in this examination had predefined, random allocations that were organized into six tests. Four of these tests had a strategic item, which was designed to evaluate a participant's selective attention; errors on these tests invalidated the respective test (Table 1). Before administration of the MBEA, each participant was given instructions and presented with sample items. All item answers were registered using a standard form.

\section{Electrophysiological auditory evaluation - mismatch negativity}

In order to obtain the MMN, we used an ICS Chartr EP 200 System type 1073 from GN Otometrics A/S connected via USB to a computer. Two reference electrodes were positioned on the participants' earlobes (A1 and A2); the active electrode on the Fpz position and the ground electrode on $\mathrm{Fp} 2$, according to the International System ${ }^{25}$. An impedance $<5 \mathrm{k} \Omega$ was maintained throughout the examination for all electrodes, as well as the difference between impedances below $3 \mathrm{k} \Omega$.

For visual distraction, a silent movie with subtitles was shown to participants during the examination. Acoustic stimuli were presented binaurally through earphones,

Table 1. Montreal battery evaluation of amusia (MBEA)-short version.

\begin{tabular}{|c|c|c|c|c|c|c|}
\hline \multirow{2}{*}{ Test } & \multicolumn{3}{|c|}{ Melodic organization } & \multicolumn{2}{|c|}{ Temporal organization } & \multirow{2}{*}{ Musical memory } \\
\hline & Scale & Contour & Interval & Rhythm & Meter & \\
\hline \multirow{4}{*}{ Items } & \multicolumn{3}{|c|}{15 pairs of melodies per test: } & \multirow{4}{*}{ Similar to melodic tests } & 14 musical phrases & 14 melodies \\
\hline & \multicolumn{3}{|c|}{7 pairs of identical melodies } & & 7 in a double meter; & 7 previously presented \\
\hline & 7 pairs & different $n$ & helodies ${ }^{1}$ & & 7 in a triple meter & 7 novel \\
\hline & \multicolumn{3}{|c|}{1 strategic item² } & & & \\
\hline Goal & \multicolumn{3}{|c|}{$\begin{array}{c}\text { Identify whether the melodies } \\
\text { heard in each pair were equal } \\
\text { or different }\end{array}$} & Similar to melodic tests & $\begin{array}{l}\text { Categorize the musical } \\
\text { phrase as a march (double } \\
\text { meter) or waltz (triple meter) }\end{array}$ & $\begin{array}{c}\text { Identify whether the melody } \\
\text { was previously presented or } \\
\text { is novel }\end{array}$ \\
\hline
\end{tabular}


and were arranged in blocks of identical stimuli (patterns), with a frequency of $900 \mathrm{~Hz}$. Occasionally, signals were substituted at random intervals by different stimuli (deviants), at a frequency of $1,000 \mathrm{~Hz}$. Both signal types were presented at an intensity of $75 \mathrm{~dB}$ hearing level, with the same duration and interstimulus interval. In terms of the MMN parameters, we analyzed the occurrence and latency, determined by the difference in time between the sound stimulus emission and the most negative deflection point of the evoked potential.

The MMN was registered as a negative peak deflection on an electroencephalogram, occurring $100 \mathrm{~ms}$ to $250 \mathrm{~ms}$ after the auditory stimulus. The MMN was obtained by subtracting the standard stimulus potential from the potential related to the deviant stimulus (Figure 1) ${ }^{20-22}$.

\section{Statistical analysis}

A descriptive analysis of the collected data was performed to characterize participants according to age, sex, schooling, length of musical study, MBEA score, and MMN occurrence and latency. Kolmogorov-Smirnov test was used to evaluate whether these variables were normally distributed, while measures of central tendency and dispersion were performed for quantitative variables.

A correlation analysis between groups included MBEA scores, occurrence and latency of the MMN, and independent variables such as age, sex, length of musical study, and education. The direction and magnitude of these correlations were defined through appropriate tests, which are presented alongside the results of the corresponding analysis in the following section. The statistical significance assumed for these correlation analyses was based on a $p$ value $<0.05$.

\section{RESULTS}

The NF1 group showed significantly reduced scores on the short MBEA compared to the control group, a phenomenon that was also observed on all MBEA subtests (Figure 2, Table 2). Both groups were similar in terms of age, sex and schooling (Table 3), and there was



*Student $t$-test; ** Mann-Whitney test

Figure 2. Box plot - Total Montreal Battery Evaluation of Amusia (MBEA) and subtest scores. Strategic items were not considered in the count of correct answers.

Table 2. Montreal Battery Evaluation of Amusia (MBEA) total and subtests scores.

\begin{tabular}{|c|c|c|c|c|c|c|c|c|}
\hline \multirow{3}{*}{ Groups } & \multicolumn{2}{|c|}{ Total MBEA } & \multicolumn{2}{|c|}{ Melodic } & \multicolumn{2}{|c|}{ Temporal } & \multicolumn{2}{|c|}{ Memory } \\
\hline & \multicolumn{2}{|c|}{84 items } & \multicolumn{2}{|c|}{42 items } & \multicolumn{2}{|c|}{28 items } & \multicolumn{2}{|c|}{14 items } \\
\hline & Mean & SD & Mean & SD & Mean & SD & Mean & SD \\
\hline \multirow{2}{*}{ NF1 patients $(n=18)$} & 57.39 & 7.92 & 26.94 & 4.94 & 18.44 & 2.50 & 12.11 & 1.97 \\
\hline & $68.30 \%$ & & $62.80 \%$ & & $65.80 \%$ & & $86.50 \%$ & \\
\hline \multirow{2}{*}{ Controls $(n=22)$} & 71.59 & 4.87 & 33.64 & 3.75 & 24.77 & 2.59 & 13.23 & 0.87 \\
\hline & $85.20 \%$ & & $80.00 \%$ & & $88.50 \%$ & & $94.50 \%$ & \\
\hline
\end{tabular}

$\%$ : Mean percentage of correct answers in the MBEA tests; SD: standard deviation.

Table 3. Participant demographics.

\begin{tabular}{|c|c|c|c|c|c|c|c|c|c|}
\hline \multirow{2}{*}{ Groups } & \multicolumn{3}{|c|}{ Gender } & \multicolumn{3}{|c|}{ Age } & \multicolumn{3}{|c|}{ Schooling } \\
\hline & Male & Female & $p$-value ${ }^{a}$ & Mean & $\mathrm{SD}$ & $p$-value ${ }^{b}$ & Middle & Higher & $p$-value ${ }^{a}$ \\
\hline \multirow{2}{*}{ NF1 patients $(n=18)$} & 6 & 12 & 0.842 & 24.17 & 5.94 & 0.902 & 6 & 12 & 0.498 \\
\hline & $33.3 \%$ & $66.7 \%$ & & & & & $33.3 \%$ & $66.7 \%$ & \\
\hline \multirow{2}{*}{ Controls $(n=22)$} & 8 & 14 & & 24.36 & 4.10 & & 5 & 17 & \\
\hline & $36.4 \%$ & $63.6 \%$ & & & & & $13.6 \%$ & $86.4 \%$ & \\
\hline \multirow{2}{*}{ Total $(n=40)$} & 14 & 26 & & \multirow{2}{*}{24.27} & \multirow{2}{*}{4.95} & & 9 & 31 & \\
\hline & $35.0 \%$ & $65.0 \%$ & & & & & $22.5 \%$ & $77.5 \%$ & \\
\hline
\end{tabular}

SD: standard deviation. Correlation coefficients - a: Fisher's exact test, b: Student t-test. 
no correlation between these variables and MBEA scores (Table 4). However, in a within-group analysis, we observed that lower MBEA values in the NF1 group tended to correlate with longer periods of musical study. This relationship did not exist in the control group (Table 4).

A short MBEA score that was below 2 SDs of the control group mean was used for the diagnosis of amusia. Occurrence of this condition was observed in $67 \%$ of patients in the NF1 group and $4.5 \%$ of the healthy controls ( $p=0.001$, odds ratio $(\mathrm{OR})=42.0$, confidence interval $(\mathrm{CI})$ : 4.5-391.6). The same tendency was verified when an isolated analysis was performed on the melodic subtest ( $p=0.002, \mathrm{OR}=21.0$, $\mathrm{CI}=2.3-191.2)$ and temporal subtest $(\mathrm{p}=0.001)$; OR and CI were not measured, because temporal impairment was not observed in the control group). There was no statistical difference between groups on the memory subtest $(p=0.115$, $\mathrm{OR}=6.0, \mathrm{CI}=0.6-59.4$ ) (Figure 2).

Diagnosis of amusia in the NF1 group showed a strong correlation with worse results on the temporal subtest of the MBEA, although impairment on the melodic subtest was also prevalent (Figure 2, Table 5). Among the six patients with NF1 without amusia, three presented with isolated temporal processing deficits, while none exhibited disruptions in melodic processing. In the control group, the only individual that met the diagnostic criteria for amusia showed impairment on the melodic, but not the memory or temporal, subtest of the MBEA.

The MMN was identified in most participants, and latency was similar in both channels. Thus, we chose the right auricular position (corresponding channel, Fpz-A2) for our analysis, since registry of the left auricular position (Fpz-A1) was absent in two participants. The MMN amplitude was not used as an evaluation parameter, as the baseline values could not be defined for several examinations (Figure 3). These measurement issues are not unique to this study and have been described by other authors ${ }^{26}$.

In the NF1 group, there was a trend toward higher latency values for lower MBEA scores ( $p=0.056$; slightly superior to the reference $\mathrm{p}<0.05$ ) (Figure 4A). In this

Table 4. Montreal Battery Evaluation of Amusia (MBEA) score and independent variables.

\begin{tabular}{|c|c|c|c|c|c|c|c|c|}
\hline \multirow{3}{*}{ Variables } & \multicolumn{8}{|c|}{ Total MBEA score } \\
\hline & \multicolumn{4}{|c|}{ Controls } & \multicolumn{4}{|c|}{ NF1 patients } \\
\hline & $\mathrm{n}$ & Mean & SD & $p$-value & $n$ & Mean & SD & $p$-value \\
\hline \multicolumn{9}{|l|}{ Gender } \\
\hline Female & 14 & 71.71 & 4.71 & \multirow{2}{*}{$0.88^{b}$} & 12 & 56.92 & 9.51 & \multirow{2}{*}{$0.732^{\mathrm{b}}$} \\
\hline Male & 8 & 71.38 & 5.45 & & 6 & 58.33 & 3.56 & \\
\hline \multicolumn{9}{|l|}{ Schooling } \\
\hline Middle & 5 & 71.60 & 3.36 & \multirow{2}{*}{$1.0^{b}$} & 6 & 59.00 & 6.42 & \multirow{2}{*}{$0.558^{b}$} \\
\hline Higher & 17 & 71.59 & 5.32 & & 12 & 56.58 & 8.72 & \\
\hline \multicolumn{9}{|c|}{ Music study or practice } \\
\hline Yes & 9 & 72.56 & 6.82 & \multirow{2}{*}{$0.45^{b}$} & 10 & 53.60 & 7.21 & \multirow{2}{*}{$0.018^{b}$} \\
\hline No & 13 & 70.92 & 3.04 & & 8 & 62.13 & 6.27 & \\
\hline Age $^{a}$ & - & - & - & $0.09^{\circ}$ & - & - & - & $0.582^{c}$ \\
\hline
\end{tabular}

Table 5. Mismatch negativity (MMN): occurrence and latency in groups.

\begin{tabular}{|c|c|c|c|c|c|c|c|c|}
\hline \multirow{3}{*}{ Variable } & \multicolumn{4}{|c|}{ With amusia } & \multicolumn{4}{|c|}{ Without amusia } \\
\hline & \multirow{2}{*}{$\mathrm{n}$} & \multirow{2}{*}{ Occurrence } & \multicolumn{2}{|c|}{ Latency } & \multirow{2}{*}{$\mathrm{n}$} & \multirow{2}{*}{ Occurrence } & \multicolumn{2}{|c|}{ Latency } \\
\hline & & & Mean & SD & & & Mean & SD \\
\hline NF1 patients & 10 & $9(90 \%)$ & 171.76 & 8.81 & 5 & $4(80 \%)$ & 139.16 & 6.11 \\
\hline Controls & 1 & $1(100 \%)$ & $160 *$ & * & 18 & $16(89 \%)$ & 166.22 & 5.67 \\
\hline
\end{tabular}

For the MMN analysis, there were three missing stimuli (volunteers that did not return to perform the MMN) tests amongst the NF1 patients: two classified as "with amusia" and one as "without amusia". In the control group, there were also three missing stimuli, all classified as "without amusia".

* It was not possible to obtain mean and standard deviation values for MMN latency in the control group with amusia, as the data corresponded to a single individual. 
group, mean latency was higher among patients with amusia $(p=0.031)$ (Table 5, Figure 4B) However, there was no significant difference between patients with NF1 and controls in terms of MMN occurrence and latency. There was also no significant difference between individuals with and without amusia, as well as between MBEA subtests. Age, sex, schooling and length of musical practice also did not correlate with the MMN results.

A
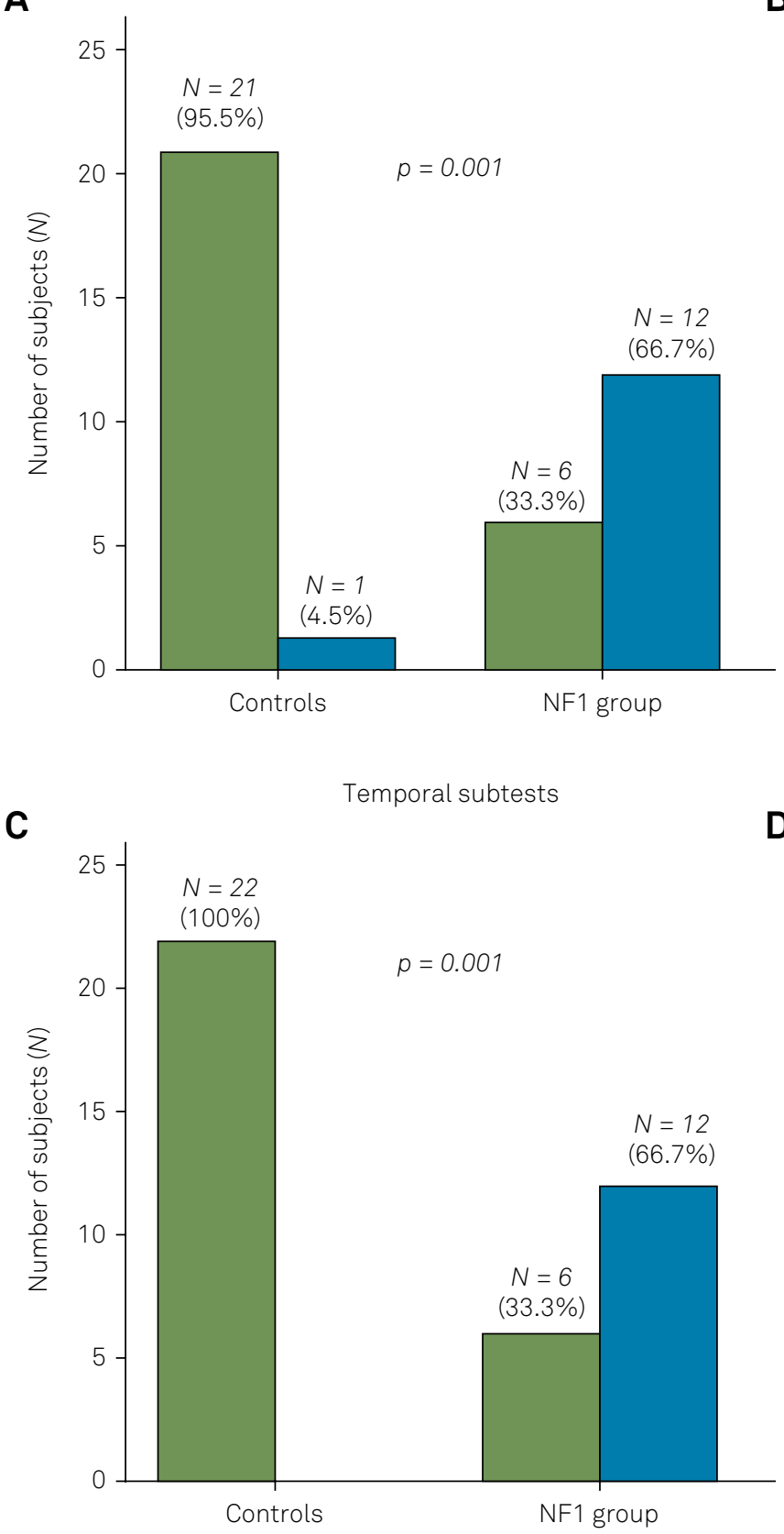

Without amusia

\section{DISCUSSION}

This is the first investigation to evaluate the prevalence of amusia in patients with NF1. Our findings revealed that the risk of amusia was 42 times greater in patients with NF1 than in healthy controls. More specifically, $67 \%$ of the NF1 patients included in this study presented with amusia, while only $4.5 \%$ of controls displayed the condition.

B

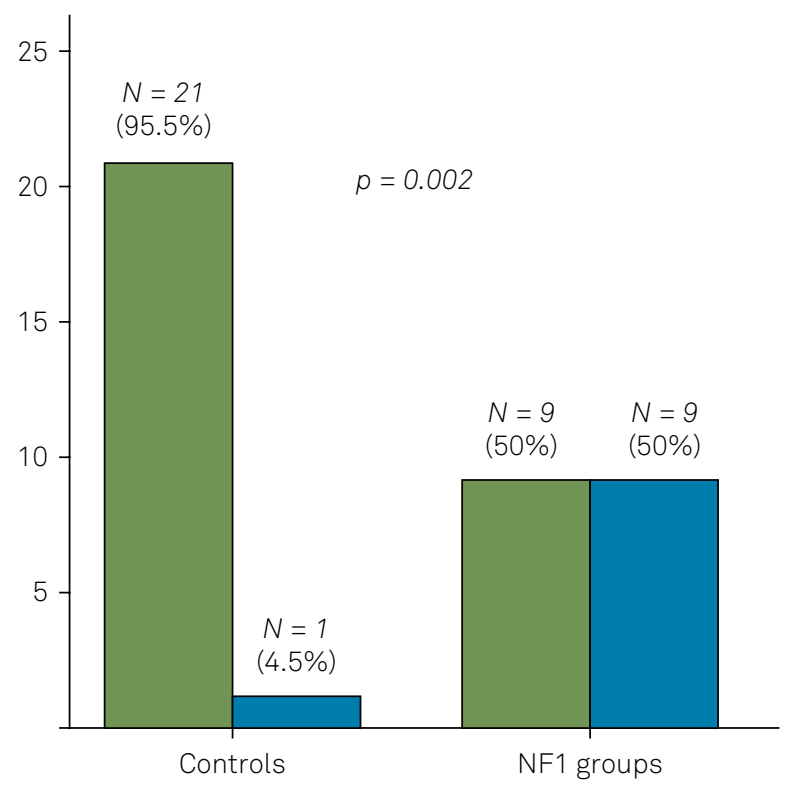

D

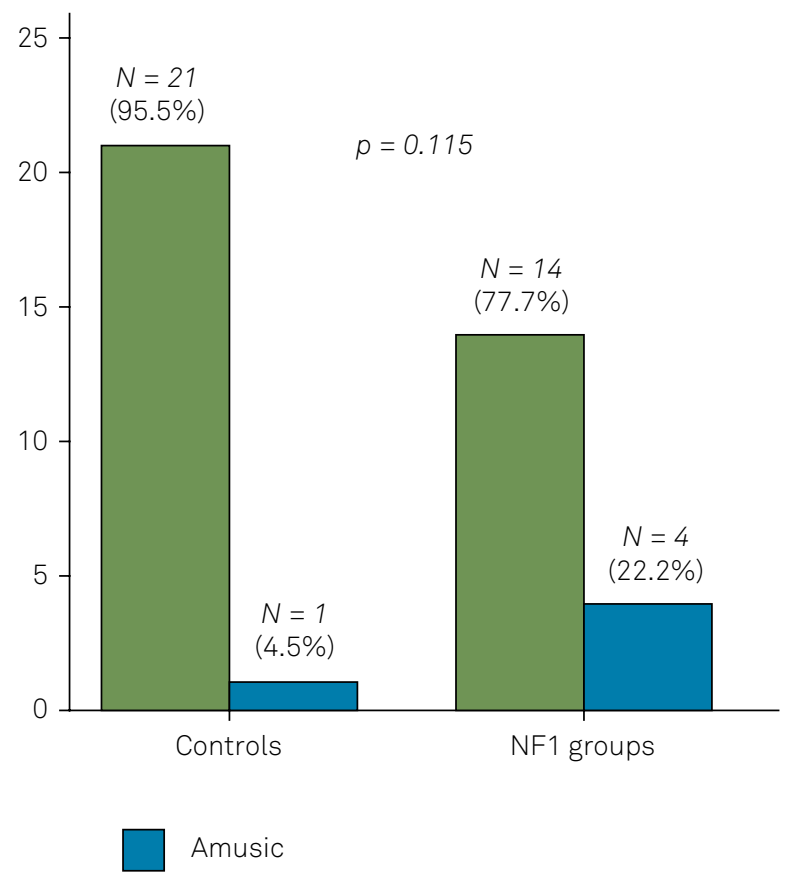


A

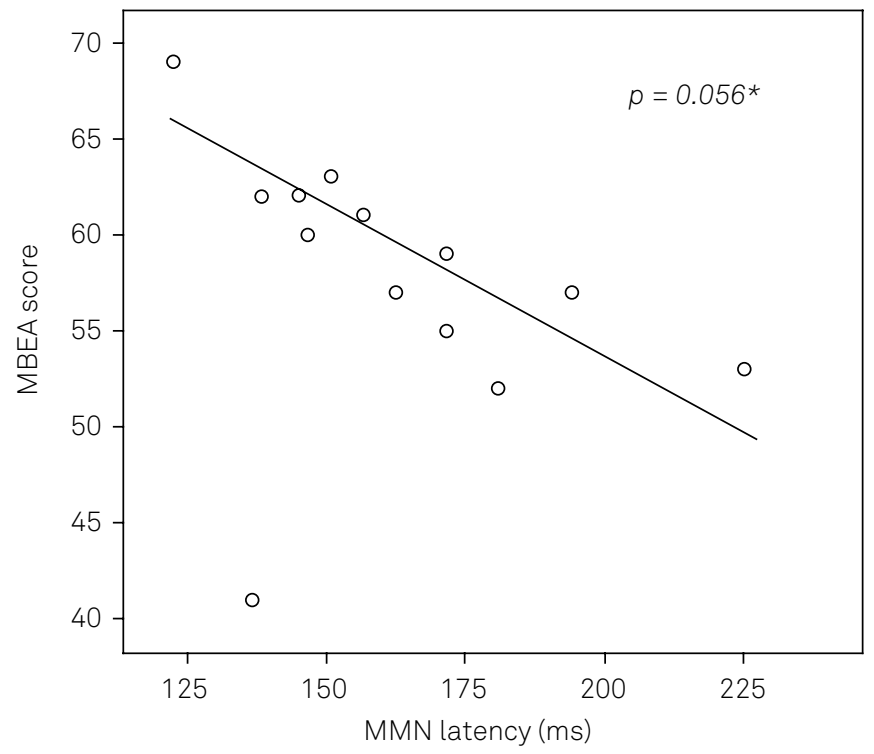

B



Figure 4. A: Scatter plot: Montreal Battery Evaluation of Amusia (MBEA) and mismatch negativity (MMN) latency in patients with NF1; * $p$-value: *Spearman's correlation test. B: Box plot: MMN latency in individuals with NF1, with or without amusia; ${ }^{*}$-value: Mann-Whitney test.

In terms of scores on the MBEA and its subtests, the NF1 group exhibited worse performance on all MBEA subtests. The impairment of musical memory was the least statistically significant. However, the number of items in the memory subtest is far smaller than other subtest groups (temporal and melodic); thus, this analysis is probably associated with low statistical power. Factors such as sex, age and education did not correlate with the MBEA scores.

Impaired temporal organization was predominant in patients with NF1, independent of a diagnosis of amusia. This finding corroborates a recent report by Batista and colleagues? which described significantly disrupted temporal auditory processing in patients with NF1. Interestingly, children and teenagers with the same impairment, but without NF1, also exhibit difficulties in perceiving music, especially in their ability to judge meter, an element of temporal musical structure ${ }^{27}$. This evidence suggests a possible relationship between a temporal auditory processing disorder and amusia in NF1.

We postulate that the impaired music perception exhibited by patients with NF1 in the current study was not related to compromised attention, as we used the short version of the $\mathrm{MBEA}^{24}$. This version of the test requires only 50 minutes, which is far less than the time associated with the full version of the MBEA (90 minutes) ${ }^{14}$. Thus, subjects may have experienced less fatigue during testing, reducing the chance of impaired selective attention and working memory ${ }^{28}$. Moreover, no error was made on the strategic item of the MBEA, that relates to selective attention; therefore, no test was invalidated. Additionally, the adjustment of sound intensity through filters, as well as soundproofing and temperature control of the test environment, reduced the likelihood that attention would be diverted to other stimuli.

Scores of the control group on the short version of the MBEA suggest its equivalence to the full version. The mean score and cutoff point for a diagnosis of amusia was similar to that employed in previous studies of congenital amusia using the full MBEA $^{14,29,30}$ and was also comparable to another study employing a short version proposed by Wise ${ }^{31}$. Moreover, the incidence of congenital amusia among controls in the present study was similar to that found in the general population ${ }^{11,12}$.

We did not find any previous studies of the analysis of the MMN in NF1. In the present study, the MMN occurrence and latency were similar between patients with NF1 and controls. However, in the analysis separated by group, a higher latency of the MMN tended to correlate with lower MBEA scores in the NF1 group but not in healthy controls. These findings are in contrast to studies evaluating the MMN in individuals with congenital amusia, who have no abnormalities in this evoked potential ${ }^{19,32}$.

In light of our electrophysiological findings, as well as the significant impairment of temporal music processing in individuals with NF1, we conclude that the amusia present in this disease may have different genetic and neurophysiological substrates than that in congenital amusia. Thus, a possible correlation with an auditory processing disorder must be considered, as well as correlations with other cognitive characteristics present in NF1 (e.g. learning difficulties and language disorders), as these impairments are absent in individuals with congenital amusia. 


\section{Acknowledgments}

We are grateful to all patients and volunteers from the Neurofibromatosis Outpatient Reference Center of the Hospital das Clínicas of the Federal University of Minas Gerais, who collaborated with this study. We also thank Ana Maria Arruda Lana and Marília NunesSilva for their support and encouragement in the initial stages; and Laís Pataro Barbosa for assistance in data collection.

\section{References}

1. Rodrigues LO, Batista PB, Goloni-Bertollo EM, Souza-Costa D, Eliam L, Eliam M et al. Neurofibromatoses: part 1: diagnosis and differential diagnosis. Arq Neuropsiquiatr. 2014 Mar;72(3):241-50. https://doi.org/10.1590/0004-282X20130241

2. Diggs-Andrews KA, Gutmann DH. Modeling cognitive dysfunction in neurofibromatosis-1. Trends Neurosci. 2013 Apr;36(4):237-47. https://doi.org/10.1016/j.tins.2012.12.002

3. Pride N, Payne JM, Webster R, Shores EA, Rae C, North KN. Corpus callosum morphology and its relationship to cognitive function in neurofibromatosis type 1.J Child Neurol. 2010 Jul;25(7):834-41. https://doi.org/10.1177/0883073809350723

4. Piscitelli O, Digilio MC, Capolino R, Longo D, Di Ciommo V. Neurofibromatosis type 1 and cerebellar T2-hyperintensities: the relationship to cognitive functioning. Dev Med Child Neurol. 2012 Jan;54(1):49-51. https://doi.org/10.1111/j.1469-8749.2011.04139.x

5. Hyman SL, Gill DS, Shores EA, Steinberg A, North KN.

T2 hyperintensities in children with neurofibromatosis type 1 and their relationship to cognitive functioning. $J$ Neurol Neurosurg Psychiatry. 2007 Oct;78(10):1088-91. https://doi.org/10.1136/jnnp.2006.108134

6. Karlsgodt KH, Rosser T, Lutkenhoff ES, Cannon TD, Silva A, Bearden CE. Alterations in white matter microstructure in neurofibromatosis-1. PLoS One. 2012;7(10):e47854. https://doi.org/10.1371/journal.pone.0047854

7. Batista PB, Lemos SM, Rodrigues LO, de Rezende NA. Auditory temporal processing deficits and language disorders in patients with neurofibromatosis type 1. J Commun Disord. 2014 MarApr;48:18-26. https://doi.org/10.1016/j.jcomdis.2013.12.002

8. Ayotte J, Peretz I, Hyde K. Congenital amusia: a group study of adults afflicted with a music-specific disorder. Brain. 2002 Feb;125(Pt 2):238-51. https://doi.org/10.1093/brain/awf028

9. Williamson VJ, Stewart L. Congenital amusia. Handb Clin Neurol. 2013;111:237-9. https://doi.org/10.1016/B978-0-444-52891-9.00024-5

10. Särkämö T, Tervaniemi M, Soinila S, Autti T, Silvennoinen HM, Laine $\mathrm{M}$ et al. Amusia and cognitive deficits after stroke: is there a relationship? Ann N Y Acad Sci. 2009 Jul;1169(1):441-5. https://doi.org/10.1111/j.1749-6632.2009.04765.x

11. Peretz I, Vuvan DT. Prevalence of congenital amusia. Eur J Hum Genet. 2017 May;25(5):625-30. https://doi.org/10.1038/ejhg.2017.15

12. Kalmus H, Fry DB. On tune deafness (dysmelodia): frequency, development, genetics and musical background. Ann Hum Genet. 1980 May;43(4):369-82. https://doi.org/10.1111/j.1469-1809.1980.tb01571.x

13. Liu F, Jiang C, Wang B, Xu Y, Patel AD. A music perception disorder (congenital amusia) influences speech comprehension. Neuropsychologia. 2015 Jan;66:111-8. https://doi.org/10.1016/j.neuropsychologia.2014.11.001

14. Peretz I, Champod AS, Hyde K. Varieties of musical disorders. The Montreal Battery of Evaluation of Amusia. Ann N Y Acad Sci. 2003 Nov;999(1):58-75. https://doi.org/10.1196/annals.1284.006

15. Peretz I. Neurobiology of Congenital Amusia. Trends Cogn Sci. 2016 Nov;20(11):857-67. https://doi.org/10.1016/j.tics.2016.09.002
16. Hyde KL, Zatorre RJ, Peretz I. Functional MRI evidence of an abnormal neural network for pitch processing in congenital amusia. Cereb Cortex. 2011 Feb;21(2):292-9. https://doi.org/10.1093/cercor/bhq094

17. Loui P, Alsop D, Schlaug G. Tone deafness: a new disconnection syndrome? J Neurosci. 2009 Aug;29(33):10215-20. https://doi.org/10.1523/JNEUROSCI.1701-09.2009

18. Loui P, Hohmann A, Schlaug G. Inducing Disorders in Pitch Perception and Production: a Reverse-Engineering Approach. Proc Meet Acoust. 2010 Apr;9(1):50002. https://doi.org/10.1121/1.3431713

19. Moreau P, Jolicœur P, Peretz I. Pitch discrimination without awareness in congenital amusia: evidence from eventrelated potentials. Brain Cogn. 2013 Apr;81(3):337-44. https://doi.org/10.1016/j.bandc.2013.01.004

20. Garrido MI, Kilner JM, Stephan KE, Friston KJ. The mismatch negativity: a review of underlying mechanisms. Clin Neurophysiol. 2009 Mar;120(3):453-63. https://doi.org/10.1016/j.clinph.2008.11.029

21. Näätänen R, Sussman ES, Salisbury D, Shafer VL. Mismatch negativity (MMN) as an index of cognitive dysfunction. Brain Topogr. 2014 Jul;27(4):451-66. https://doi.org/10.1007/s10548-014-0374-6

22. Bartha-Doering L, Deuster D, Giordano V, am Zehnhoff-Dinnesen A, Dobel C. A systematic review of the mismatch negativity as an index for auditory sensory memory: from basic research to clinical and developmental perspectives. Psychophysiology. 2015 Sep;52(9):1115-30. https://doi.org/10.1111/psyp.12459

23. Pen MG, Mangabeira-Albernaz PL. Desenvolvimento de teste de logoaudiometria: discriminação vocal. In: Anales do 2 Congresso Pan americano de Otorrinolaringologia y Broncoesofasologia, 2, 1973, Lima, Peru. p. 223-6.

24. Nunes-Silva M, Haase VG. Montreal Battery of Evaluation of Amusia: validity evidence and norms for adolescents in Belo Horizonte, Minas Gerais, Brazil. Dement Neuropsychol. 2012 Oct-Dec;6(4):244-52. https://doi.org/10.1590/S1980-57642012DN06040008

25. American Clinical Neurophysiology Society. Guideline twelve: guidelines for long-term monitoring for epilepsy. J Electroneurodiagn Technol. 2008 Jun;25(3):170-80 https://doi.org/10.1097/WNP.0b013e318175d472

26. Sinkkonen J, Tervaniemi M. Towards optimal recording and analysis of the mismatch negativity. Audiol Neurootol. 2000 MayAug;5(3-4):235-46. https://doi.org/10.1159/000013885

27. Olakunbi D, Bamiou DE, Stewart L, Luxon LM. Evaluation of musical skills in children with a diagnosis of an auditory processing disorder. Int J Pediatr Otorhinolaryngol. 2010 Jun;74(6):633-6. https://doi.org/10.1016/j.ijporl.2010.03.008

28. Unsworth N, Robison MK. The influence of lapses of attention on working memory capacity. Mem Cognit. 2016 Feb;44(2):188-96. https://doi.org/10.3758/s13421-015-0560-0

29. Cuddy LL, Balkwill LL, Peretz I, Holden RR. Musical difficulties are rare: a study of "tone deafness" among university students. Ann N Y Acad Sci. 2005 Dec;1060(1):311-24. https://doi.org/10.1196/annals.1360.026 
30. Pfeifer J, Hamann S. Revising the diagnosis of congenital amusia with the Montreal Battery of Evaluation of Amusia. Front Hum Neurosci. 2015 Apr;9:161. https://doi.org/10.3389/fnhum.2015.00161

31. Wise K. Understanding "tone deafness": A multi-componential analysis of perception, cognition, singing and self-perceptions in adults reporting musical difficulties [Doctoral degree] Keele, UK: Keele University; 2009.

32. Moreau P, Jolicoeur P, Peretz I. Automatic brain responses to pitch changes in congenital amusia. Ann N Y Acad Sci. 2009 Jul;1169(1):191-4.

https://doi.org/10.1111/j.1749-6632.2009.04775.x 